\title{
Chapter 3 \\ Intersections of Culture, Language, and Mathematics Education: Looking Back and Looking Ahead
}

\author{
Marta Civil
}

\begin{abstract}
This paper draws from a research agenda focused on the interplay of culture, language and mathematics teaching and learning, particularly in working-class Mexican-American communities in the United States. Drawing on data collected over several years, I emphasize the need for a coordinated effort to the mathematics education of non-dominant students, an effort that involves teachers and other school personnel, the students' families, and the students themselves. Through the voices of parents, teachers, and students, I illustrate the resources that non-dominant students bring to school but often go untapped, and the tensions that this may carry. Following a socio-cultural approach grounded on the concept of funds of knowledge, I argue for the need to develop stronger communication among the interested parties to develop learning experiences in mathematics that build on the knowledge, the language and cultural resources, and the forms of participation in the students' communities.
\end{abstract}

Keywords Culture $\cdot$ Language of learning and teaching - Immigrant students In-school and out-of-school mathematics - Parental engagement in mathematics

That's in mom's home. Let's do it the way that we do it in the school. [Dina]

Dina was a fifth-grade teacher (students are ten years old) in a Teacher Study Group focused on issues around mathematics, language, and culture. She was teaching in a school in a working-class community with a large number of students of Mexican origin, some of whom were classified as English Learners (ELs). In the excerpt below, Dina is reflecting on some of the challenges she thinks students face in regard to mathematics learning.

M. Civil ( $\square)$

The University of Arizona, Tucson, USA

e-mail: civil@math.arizona.edu

(C) The Author(s) 2018

G. Kaiser et al. (eds.), Invited Lectures from the 13th International Congress

on Mathematical Education, ICME-13 Monographs,

https://doi.org/10.1007/978-3-319-72170-5_3 
Dina: One of the problems that I saw here was that we were teaching multiplication skills to the children, and I thought, 'Oh, that is something easy that the parents at home can help the children.' Well we ended up with totally different answers, and the children came back with the homework, and the answer was not even close to what the answer was, and they start to say to us, 'But that's an approximation.' ... Then we asked some parents to come to the school and teach us what they were doing at home, and they were doing something that we never understood, but it was close to the answer. They didn't understand that math is a precise subject. You cannot change the right answer unless it's a ... what is it... what is the one that is close?

Interviewer: An estimation.

Dina:

An estimation, but if you do multiplication you have to give me exactly the answer, and for a while, division and multiplication became a problem because we couldn't get the children, you know, they learned it at home, how to do things, and they came, and they do it on the board, and I didn't know what were they doing. ... I don't know exactly what they were trying to teach the children, but now the children are doing the math the way we asked them to do it. They are still making mistakes, but they are getting better. At least they understand.

Interviewer: Do the kids ever complain to the moms, that 'that's not the way my teacher does it'?

Dina: $\quad$ No, they did it the other way; 'Well, that's not the way my daddy does it at home. This is not the way my mom does it. It's the other way.' Then we ask them, 'Come to the board; we want to learn.' But we never, at least I never understood how they got the answers.... We talked to the parents, and we explained to them that we need to be precise, and we need the correct answer, and we explain how we teach it here, how we do it. And the question was, 'Well, what if he doesn't know?' 'Well you tell them to come early in the morning, and we will help them here.' We didn't want to say don't do it but... And now every Wednesday we are teaching division and multiplication, and the children are doing it the way we ask. This Wednesday when we did it, Eliseo said, 'Oh no, my mom did it different.' And he went to the board and did it that way, and I said 'Yes, but that's in mom's home. Let's do it the way that we do it in the school.' And it was again very close, but not the answer. It was an approximation. It was an approximation. 


\subsection{School Versus Home}

The opening vignette illustrates the main theme that I will address in this paper, namely a tension between the school way and the home way. Differences between parents' ways of doing mathematics and the ways that their children may be learning at school are quite typical and can be attributed to generational changes in approaches to teaching and learning. However, as I have argued elsewhere (e.g., Civil and Planas 2010), when this is placed in the context of non-dominant communities whose knowledge is often not recognized or valued, the implications need to be considered. In the context of the work I report here, the non-dominant communities are working-class and of immigrant origin, largely from Mexico. In several cases, the parents were schooled in Mexico while their children have been mostly schooled in the United States. Suárez-Orozco and Suárez-Orozco (2001) underscore the difficulties that immigrants often face as they try to navigate the culture from their country of origin and that of their new country. In particular, "Children of immigrants become acutely aware of nuances of behaviors that although 'normal' at home, will set them apart as 'strange' and 'foreign' in public" (pp. 88-89).

Some of the differences in the ways of doing mathematics may be attributed to cultural aspects, for example, different algorithms being used in different countries. But underlying the home-school tension captured in the vignette presented above is the concept of valorization of knowledge (Abreu 1995). In her study of how children experienced the relationship between home and school mathematics, de Abreu presents an interview with 14-year-old Severina, whose father is a sugarcane worker in rural Brazil:

Interviewer: Can you tell me what you think about the way your father did the sums, is it the same or different from the way you learned in school?

Severina: It is a different way, he does it in his head, mine is with a pen.

Interviewer: Which do you think is the proper way?

Severina: School.

Interviewer: Which do you think gives a correct result?

Severina: My father.

Interviewer: Why?

Severina: Because I just think so (p. 137).

I often use this exchange between Severina and the interviewer to illustrate the concept of valorization of knowledge. While Severina knows that her father can do computation in his head and get the right answer, she still believes that the school way with pencil and paper is the proper way. What are the implication for children like Severina or the ones in the opening classroom vignette when their parents' ways are different from the school's ways? What message is Dina (the teacher in the vignette) sending when she says, "Yes, but that's in mom's home. Let's do it the way that we do it in the school"? 


\subsection{Some Context}

This paper draws on over 20 years of a research agenda focused on the interplay of culture, language and mathematics teaching and learning, particularly in working-class Mexican-American communities in Southern Arizona, in the United States. It is important to understand that there are wide differences in these communities, with some families having been there in Arizona for generations. The area was part of Mexico until the Gadsden purchase treaty in 1853 (Sheridan 1995). A popular saying is that "we didn't cross the border, the border crossed us." Other families are recent immigrants. In some households the primary language is Spanish, while in others it is English; many families are bilingual (or multilingual). In many homes, children may speak English among themselves and use Spanish to speak with their parents and older relatives. Overall these students attend de facto segregated schools in that a majority of the students in their school is of Mexican origin and working-class. Students in these schools tend to do less well by traditional testing measures than those in schools in middle to upper class neighborhoods with fewer numbers of students of non-dominant backgrounds.

My approach to both research and outreach in schools in working-class, immigrant origin communities rejects a deficit view of these communities that tends to blame children and their families for their "lack of success" in school. Instead, my work is grounded on the theory behind the Funds of Knowledge for Teaching project (González et al. 2005). The main premise is that in all communities and households there is knowledge, resources, experiences that allow families to get ahead. Moll et al. (2005) define funds of knowledge as "these historically accumulated and culturally developed bodies of knowledge and skills essential for household or individual functioning and wellbeing" (p. 72). I argue that our obligation as educators, teachers, researchers is to learn about and from these funds of knowledge and build on them for the advancement of students in school.

Hodge and Cobb (2016) describe this approach as an example of the "Cultural Alignment Orientation", which they say "has become the default theoretical framework for research on issues of equity in mathematics education" (p. 2). In this orientation, the authors say that the focus is on "aligning the practices established in the mathematics classroom with the out-of-school practices in which students participate. Given this framing, it becomes critical to learn about and leverage students' out-of-school practices as resources to address inequities in learning opportunities" (p. 2). The authors argue for a "Classroom Participation Orientation," which they consider broadens our approach to developing equitable approaches to teaching and learning. In their view, "the Classroom Participation Orientation is grounded in the view of culture as a network of local hybrid practices that people jointly constitute as they negotiate their places in specific settings such as the mathematics classroom" (p. 4). While the two orientations are different, the authors themselves note that the Funds of Knowledge project, which is at the basis of much of my work, has moved from the notion of alignment to also incorporate that of participation, particularly building on the concept of hybridity. Following a 
Funds of Knowledge orientation means that the concepts of resources, participation, and valorization are central to the data analysis (Civil 2002b, 2016a).

An underlying question in my work has been how to develop mathematical learning experiences that are culturally responsive in the sense that they reflect and build on the learners' everyday/out-of-school experiences, but are also responsive to the mathematical agenda that needs to be met (Civil 2002b, 2007). As we started bringing in the voices of parents through their participation in mathematics workshops where there is an exchange of experiences, our approach has somewhat moved back and forth between the notion of alignment, in that we have a deep interest in out-of-school mathematical experiences and the notion of participation, particularly as we see students and families navigate multiple spaces (Díez-Palomar et al. 2011; Menéndez et al. 2009). Underlying this work is a need for a two-way dialogue between home and school about mathematics (Civil 2002a; Civil and Andrade 2003; Civil and Planas 2010). In the next section I look at some avenues towards this two-way dialogue.

\subsection{Towards a Two-Way Dialogue Home-School}

In the opening vignette it seems that some parents had ways of multiplying that were different from what the teachers were teaching. Dina tried to learn them, when she says "Then we asked some parents to come to the school and teach us what they were doing at home, and they were doing something that we never understood, but it was close to the answer" or later on when she says that she invited students to come to the board and show how their parents had taught them, "Come to the board; we want to learn.' But we never, at least I never understood how they got the answers." Throughout the vignette, Dina provides evidence that she tried to understand the methods but did not succeed. Dina did not feel comfortable in her understanding of mathematics and in fact in that same interview she acknowledged that if it were up to her she would not be teaching mathematics. Dina is not alone. Over the years, I have shown teachers and preservice teachers different algorithms that students may bring to class from home and I have noticed their trepidation (Civil 2016b). Dina opted for making sure that the children learned the school method and that they used that one while in school. She wanted parents to understand that there is a certain way that children are being taught, that is different from how they do it at home, and as she says "we didn't want to say don't do it but..." and does not finish the sentence:

We talked to the parents, and we explained to them that we need to be precise, and we need the correct answer, and we explain how we teach it here, how we do it. And the question was, 'Well, what if he doesn't know?' 'Well you tell them to come early in the morning, and we will help them here.' We didn't want to say don't do it but...

This situation leads to several unanswered questions such as, were the parents' methods incomplete and indeed producing only an approximation? Even if that was 
the case, was there some mathematics in them worth exploring? How could the teachers have turned this source of knowledge from the parents into a learning opportunity? Would the teachers have had the support from the school administration? What role does valorization of knowledge play? Closely related to issues of valorization of knowledge and whose knowledge is valued, are issues of power:

The border between knowledge and power - can be crossed only when educational institutions no longer reify culture, when lived experiences become validated as a source of knowledge, and when the process of how knowledge is constructed and translated between groups located within nonsymmetrical relations of power is questioned. (González 2005, p. 42)

How can we address these issues of power and valorization of knowledge when working with teachers, parents, and students? This has become a central question in my work. One activity I have been using is to have parents and teachers read quotes that other parents and teachers have said in relation to issues on the teaching and learning of mathematics. The quotes are posted around the room and the participants are to stand by the one that speaks to them the most (either because they agree with it, or they do not, or any other reason). One of the quotes I have used was related to the opening vignette and read as follows:

\footnotetext{
We are teaching division and multiplication, and the children are doing it the way we ask. This Wednesday when we did it, Eliseo said, 'Oh no, my mom did it different.' And he went to the board and did it that way, and I said 'Yes, but that's in mom's home. Let's do it the way that we do it in the school.'
}

One mother and one teacher stood by that quote and this is what each said:

Mother: I identified with this quote because I did that with my child and it seems that I confused him and so the part on "let's do it the way we do it in school", we need to get involved and learn the way they teach it at school so that we can continue [the support].

Teacher: I do have students who say my mom/dad taught me this way, and for me, I do have to teach them certain ways but I encourage them if mom and dad want to teach them a different way, then my student has the strategy from school and the one from mom and dad and they can check and make sure that both answers match up, so they can check twice...

These are different reactions to the same quote. The mother underscores the importance of her learning the way they teach it at school so that she can support her child. This is most likely why she joined the project. As discussed elsewhere (Civil et al. 2005), originally parents joined a mathematics project to be able to help their children. However, in reading this mother's comment, I wonder, does she recognize the value of her own methods? Does she appreciate the potential richness of multiple methods? Is she in a way according more value to the school method than to her own method? On the other hand, the teacher, while acknowledging the institutional pressures she feels to teach specific methods, is open and in fact encourages children to bring other ways from home. Her approach is what I characterize as resource-based. This teacher views home knowledge as an asset 
towards her students' education. How do we capitalize on a resource-based view that encourages the use of home knowledge without pushing away parents who feel that their role is to learn the school ways? But also, how do we strike a balance between recognizing and building on home knowledge while recognizing that "merely glorifying popular knowledge does not contribute to the process of social change" (Knijnik 1993, p. 25).

Bringing quotes such as the one in the vignette for discussion with parents and teachers is an effective way to promote a dialogue around teaching and learning mathematics. Other approaches have included teams of parents and teachers presenting mathematics workshops to other parents in the community (Civil and Bernier 2006), parents and teachers participating in mathematics workshops together, parents visiting a mathematics classroom and then debriefing the visit (Civil and Quintos 2009), and teachers visiting the homes of some of their students to learn about the family's funds of knowledge. In what follows, I briefly present some key findings from these different avenues to promoting a dialogue between home and school around mathematics teaching and learning.

\subsection{Cultural Aspects}

Many immigrant parents (like everybody else) bring deeply rooted views of what mathematics teaching and learning should look like, for example expressing surprise at physical arrangements of the classroom where students are sitting in groups, some with their backs to the board or to the teacher's desk; or showing concern when students in 3rd grade and higher do not know their multiplication facts yet. But at the same time, as parents engage as learners of mathematics themselves, some develop an appreciation for a focus on conceptual understanding and not only memorization of facts; or an appreciation for joint problem-solving. Yet, as the example of the mother's reaction to the quote indicates, there are some parents who seem ready to give into the school ways. This points to the complexity of the situation where parents, and in particular immigrant parents, are interpreting what they see through their own cultural experiences but also are listening to their children and trying to make sense of their schooling experience. Over the years, we have collected evidence from mothers mentioning the tension they feel when they try to teach their children how they were taught (e.g., Civil and Planas 2010; Civil et al. 2005).

Parents and children are likely to have other ways of doing mathematics, or interpret problems in ways that are based on their everyday experiences and may be different from what the teacher expected. What can teachers do? Some express concern as to how to work with these different approaches. Their concern may be based on their own understanding of mathematics like Dina's case in the vignette, where she tried to understand but did not succeed. Other teachers seem comfortable encouraging students to use strategies that their mom or dad may have taught them, like the teacher earlier whom I described as having a resource-based approach. 
The excerpt that follows captures some of the complexity that teachers have expressed on the issue of home versus school mathematics. Caroline was a $6^{\text {th }}$ grade teacher who was reflecting on the challenges and advantages that children in general, and Latina/o children in particular faced in regard to mathematics learning.

Caroline: The Latino children, if their parents came from Mexico, then they probably did it a different way than what they did here, and even the algorithms maybe look a little different. So, I think that causes part of the problem. I think maybe part of it may be language and to translate, some of them, you know especially the students whose first language is Spanish ...

Interviewer: So what do you think are the advantages that these same children bring to the classroom?

Caroline: I think it's, like when you're making the connection, if you are doing it orally they may see it in a little different way and if, if you're discussing it, the students build off of each other ... so I think that's one; and then also even while you're discussing, even if you're looking at algorithms or something, they're going to be like "Oh well, my dad does it this way" or "My mom does it this way." And so, then you're bringing in another way, so that they're seeing maybe even a third or a fourth or a fifth way to attack a problem.

This excerpt represents what teachers in our work have often said. They are aware that students may have other ways to do mathematics particularly in the case of children of immigrant origin but they do not all see them as an advantage or a challenge. Caroline first refers to this as a possible problem, "So, I think that causes part of the problem" but then at the end of the excerpt these different algorithms are seen as an advantage, "And so, then you're bringing in another way, so that they're seeing maybe even a third or a fourth or a fifth way to attack a problem." Woven throughout Caroline's excerpt is the issue of language, which she sees as a potential problem when children have to go back and forth between English and Spanish. But she did not discourage the use of both languages and in fact she emphasized students discussing mathematics and sharing ideas, which is how she would learn about knowledge from home, "Oh well, my dad does it this way" or "My mom does it this way." In the next section I focus on language issues, which are particularly relevant when working with students and families whose home language is different from that of the school.

\subsection{Language Aspects}

It is important to briefly describe the language policy in Arizona to provide some context. In 2000, Proposition 203 was passed, which had the effect of limiting access to bilingual education for students who had been classified as English language learners (ELLs). Instead ELLs were to be taught with structured English 
immersion. Furthermore, in 2006 additional legislature established what is known as the 4-h English requirement, which means that ELLs were to receive $4 \mathrm{~h}$ of English language instruction daily. Considering that a school day has about $7 \mathrm{~h}$ of instruction, what does this mean for the learning opportunities of ELLs? The idea behind this approach was that students would be proficient in one year and thus be able to move out of the 4-h block. Research has documented that it takes longer than one year for students to become proficient in the command of the language needed for schooling purposes (Cummins 2000). As Gándara and Orfield (2012) point out, the case of Arizona is particularly important because, "having spawned a series of anti-immigrant and highly restrictionist language policies, Arizona stands as the embodiment of this struggle, and pending legal decisions in that state have the potential to reinforce these hegemonic practices and shape the way that English learners are educated across the U.S. for some time to come" (p. 9). But this, I argue, is relevant not only for the U.S., but for any country that is faced with educating children whose home language(s) is different from the language of instruction. As it has been pointed out, discussion on language policy in schools are closely related to issues around immigration and the education of immigrant students (e.g., Alrø et al. 2009; Barwell et al. 2016; Civil 2012; Gándara and Orfield 2012; Wright 2005).

What are the implications on different language policies on students' mathematics education? This is a broad question that cannot be fully addressed in this chapter, but I can certainly offer some snippets based on my research with parents, teachers, and students. A main finding is the impact of language policy on parental engagement in their children's mathematics education. In Acosta-Iriqui et al. (2011), we present a contrasting case of two states, Arizona and New Mexico, with radically different language policies. Through parents' voices we hear how their engagement and feeling of confidence at being able to help their children were drastically different in the two contexts. Many of the parents in the research studies in Arizona had experienced bilingual education with some of their children and then saw the switch to structured English immersion for their other children. The following quote captures the frustration of Verónica whose child was in bilingual classrooms for kinder and first grade but was moved to an English only classroom in second grade:

\footnotetext{
I liked it while they were in a bilingual program, I could be involved .... When he was in kindergarten ... I even brought work home to take for the teacher the next day. In first grade, it was the same thing, I went with him and because the teacher spoke Spanish, she gave me things to grade and other jobs like that. My son saw me there, I could listen to him, I watched him. By being there watching, I realized many things. And then when he went to second grade into English only and with a teacher that only spoke English, then I didn't go, I didn't go.
}

On a different occasion, Verónica also shared that she felt comfortable with her knowledge of mathematics and that she could probably help her son (by then in middle school) but that he did not come to her for help because he did not feel comfortable translating from English into Spanish so that she could understand the problems. Hence, while he could communicate in Spanish with her, he did not have 
the level of Spanish that would allow him to converse about mathematics. Would this be different, had he stayed in bilingual classes?

The question of how to teach mathematics in multilingual contexts has been widely studied (e.g., Barwell et al. 2016) and is certainly a complex situation tied to social and political considerations. In my specific context where it is essentially a Spanish/English situation and given the geographical location so close to Mexico, it seems that providing access to a solid bilingual education for all students would be a benefit to all. As one of the teachers said on reflecting on the advantages that his students brought to the classroom: "The ability to be bilingual, biliterate, I think is a huge advantage. I think that where we are in our country ..., so close to the border, the ability to speak two languages is not a hindrance, it's an advantage. I think you have more opportunities available to you."

Up to this point the focus of this paper has been on looking back at some of my work with parents and teachers around the general theme of seeking ways to connect home and school in relation to the teaching and learning of mathematics. The children are of course at the center, since they are often caught in the middle, trying to navigate both worlds, home and school. In what follows, I present the case of a student, Larissa, to further illustrate the intersection of language, culture, and mathematics education.

\subsection{The Case of Larissa}

Larissa arrived to the United States three months into the school year, at the age of 13. In Mexico, she had attended a bilingual (Spanish/English) school for most of her schooling, but based on the English placement test she was placed in classes with other students classified as ELLs, but that I will describe as bilingual learners. ${ }^{1}$ This meant that for all their classes but an elective and maybe one more class, the bilingual learners were segregated from the students who were considered proficient in English. This case is an example of what Valdés (1998) also found in her study where ELLs were segregated from non-ELLs, thus resulting in two schools within one school. Furthermore, many schools in my local context are already de facto segregated by ethnicity and social class. For example, the school that Larissa attended was at that time 95\% Latino/a, 25\% ELLs and $85 \%$ eligible for the free or reduced-price lunch program.

I am focusing on Larissa as representative of the case of many adolescent students who have to adapt to different cultural and language norms while keeping up with their academic learning and going through typical adolescence growing pains. Suárez-Orozco et al. (2009) noted that in general, recent immigrant youth

\footnotetext{
${ }^{1}$ While students whose home language is not English are often labeled as ELLs, a label that emphasizes what they "lack" (i.e., English), I prefer the term "bilingual learners" as it emphasizes that they know two languages (and in some cases more than two), even if it is with different levels of proficiency.
} 
have positive attitudes towards learning and show optimism for their future. However, as years go by, things can change, "despite their initial academic advantage, for nearly all immigrant groups, length of residence in the United States appears to be associated with declines in academic achievement and aspirations." (p. 714).

Larissa seemed to fit the profile of the academically ready learner upon arrival, as portrayed by Suárez-Orozco et al. (2009). Her knowledge of mathematics was sound and she soon emerged as a leader in mathematical discussions in the class. She was not happy about being in the segregated section for bilingual learners because, as she said in an interview three months after her arrival: "I don't really like the classes with everyone speaking Spanish. I wouldn't like to forget all the English I learned in elementary school." In that same interview, she went onto saying that she preferred English to Spanish and that if she could, she would speak mostly in English. She made friends who were English dominant and she made a clear effort to work on her English. She also shared that she was happy to be in this school because it offered more electives than her prior school in Mexico. An interview with her mother also confirmed that Larissa was happy at school: "She doesn't want to leave school. She likes it here. Larissa expresses very little of what she feels. But, what she has always told me, 'Mom, I don't want to go. I want to be here at school. I've liked it very much"' (Civil and Menéndez 2011, p. 55).

Elsewhere I have discussed the effect on students' ability to engage in mathematical discussions when access to their home language is encouraged (despite the language policy in place) (Civil 2011; Civil and Hunter 2015). Here I just give a brief illustration of the role of language in communicating a mathematical idea. Larissa was asked to explain a probability game they had just been working on to the next class, a group of $6^{\text {th }}$ graders (so, a year younger), who had just entered the classroom:

Larissa: We played a game that's called the multiplication game and the rules are that, two players that are A and B, take turns rolling two number cubes, and when, the, if the product of the numbers rolled is an odd, is an odd number, player A wins a point, and if the product of the numbers rolled is even, player B wins a point. ¿Lo decimos en español? [Do we say it in Spanish?] ...

Larissa: Es un juego que se llama multiplication game; entonces, dos jugadores, que son el A y el B, toman turnos tirando dados. Entonces, cuando tiras dos dados, ese número lo vas a multiplicar por el otro número del otro dado, y si el número es impar, el player A gana un punto; si el número es par, multiplicándolo, el player B tiene un punto. ¿Ya me entendieron? [It's a game called multiplication game; so, two players, which are A and $B$, take turns rolling dice. So, when you roll two dice, you are going to multiply that number by the number on the other die, and if the number is odd, player A gets a point; if the number is even, multiplying it, player B has a point. Did you all get it?] 
As soon as she switches to Spanish, Larissa appears more relaxed and engaged with the audience. While she was speaking in English she was mostly looking at the handout where the game was explained. When she turns to Spanish, while she still looks at the handout, as soon as she moves away from a literal translation of "if the product of the numbers rolled is..." and says "So, when you roll two dice, you are going to multiply that number by the number on the other die," she is looking at the students and using her hands to gesture in the air the two numbers that are being multiplied. Granted, her expression is not precise when she says "and if the number is odd, player A gets a point; if the number is even, multiplying it, player B has a point", as it is not clear which "number" she is referring to. It seems implicit that she means the product but she does not express it with this level of precision. Earlier in the discussion of the problem she had found the word "product" confusing, something that is not uncommon for students (note that the word in Spanish is "producto", which is not that different but it is one of these terms that have a specific meaning in mathematics, different from its meaning in everyday life). I argue that though her explanation may have lacked some precision, she probably reached the 6th graders (also bilingual learners) better than through her reading of the problem in English.

When Larissa first arrived, she would take notes in class, including copying the problems from the book into her notebook. No other student in the classroom was doing that. When I asked her about this, she said that it helped her study. The notebook is part of Mexican schooling. Students have a notebook for each of their subjects and they take notes from what is on the board and do their work there. It becomes a record of what they are doing. In contrast, in the many schools I have been in for my research, I have seen very limited use of notebooks, and in fact little emphasis on students taking notes and writing in the mathematics classroom. As part of the current standards in place in mathematics education, there is an expectation that students communicate about mathematics, explain and justify their reasoning. Would developing the habit of keeping a notebook help towards this goal? Are teachers aware that students who have been schooled in Mexico already bring this habit of study? It is important to note that by April of that first year, Larissa was no longer using a notebook. As the teacher and I were trying to develop norms that involved students writing explanations in mathematics using a blank sheet of paper (instead of trying to squeeze in their writing in the handouts they were working on), I pointed out to Larissa's group that she knew how to do this:

Marta: Larissa knows this because she usually does it, though lately she seems to have picked up other habits...

Larissa: Oh, but now I'm here. Over there [Mexico], it's another story.

That the academic expectations between school in Mexico and school in the United States were perceived as quite different became evident in the interviews with parents. For example, Larissa's mom commented that the school should expect more since what she saw her daughter doing was very easy for her. This is something that other parents and students have noted in different interviews, where they mention that what they are doing in mathematics is something that they had 
already seen in Mexico. Larissa indeed confirmed this in her first interview (three months after her arrival). Larissa's mother also brought up that while she had seen her bring some homework at the beginning, she was not seeing that anymore. Another mother who was part of the same interview said the same thing about her son. They both adamantly said that if they were in Mexico, they would have much more homework (Civil and Menéndez 2011). In a different group interview with immigrant parents including Larissa's mother, the group brought up several aspects that they all agreed that were stricter in schools in Mexico. They mentioned that the school should have more homework, demand more from the students, expect them to bring tools (pens, notebooks) to the classroom, and ask for higher quality products from the students. As one mother said, "here they put any scribble on the notebook, or on the sheet they bring from school and that's it." Below is an excerpt for that interview:

Marcos:

[They should] give them homework so that they bring it home, so that we can see what kinds of mathematics they are doing; because there are many children who don't bring any; my daughter doesn't bring any, they don't give her any

Iliana: $\quad$ Mine neither, I always ask her

Mila (Larissa's mother): Besides giving them homework, they need to demand more [from the children], because what I see, with my daughter and school here and school in Mexico, they should demand more, because for her it's very easy here and then she just kind of glosses over... and in addition to more demanding, the school should be stricter with them... they are too lax.

I move now to Larissa the following year. She was placed in the algebra class which is the highest level of mathematics at the middle school. She was also no longer in the segregated section for bilingual learners, hence taking all her classes with students who spoke English (though with different levels of proficiency, but had met the requirements to be in those classes). Furthermore, she was taking some electives available only to students in gifted education. So, by these indicators she seemed to be doing quite well academically. Towards the end of that year I had one more interview with her. I asked her to reflect on her almost two years at that school and what her impressions were:

Larissa: What I like about the school?

Marta: Yes.

Larissa: Nothing ... So, nothing is really all that interesting; I mean I think that for someone to like something, the teacher has to be more sociable and make it more engaging so that we do the work with more interest.

It could be that Larissa was acting like many young people her age. It could also be that she was not being challenged enough since the only class she said she liked was the one that was for gifted students. What was interesting to me in this second 
interview is that she did not seem as enthusiastic about the school as in the first interview. Even more interesting were her comments about her language preference. Recall that in the first interview she had said that she preferred English over Spanish. In this second interview, we talked about how she was no longer in the section for bilingual learners and how there was much more English being used around her. While she spoke English to some of her peers, she spoke Spanish to others:

Larissa: I don't like to speak English much.

Marta: How come?

Larissa: I don't know.

Marta: It's interesting because last year you told me that you wanted to speak in English.

Larissa: No, I just wanted to practice it.

Larissa: I hardly like it [English].

Marta: What is it that you don't like about English?

Larissa: That I haven't learned it well yet... that is, there are times where I need to stay quiet because I feel embarrassed if I don't say something well. So, that's the reason.

This exchange points to the difficulty that immigrant students may face when trying to fit in an environment when they do not feel comfortable with the dominant language yet. Larissa's story traces the journey from her perhaps initial optimism when she first arrived since she already knew some English to the realization that it takes longer than a year to have a good command of another language. It is worth noting what Matilde, the mathematics teacher of the bilingual learners, said when reflecting on what happens when they move to the "regular" classes.

Matilde: I work only with ELL students ... Our kids feel afraid to be in the regular classroom because they feel the other kids have the power. So, even if I have a very brilliant a kid, he goes to a regular classroom, and he is going to be student $X$ [meaning anonymous]. Because he is not going to be that brilliant because they're going to ask them questions in English so they don't know how to explain themselves and they're going to be quiet. So they're going to be, relegated to the back of the class. So they are afraid to go to a regular class.

The case of Larissa highlights some of the issues that immigrant students face in a different school setting. Larissa brought multiple resources with her, such as study and work habits (e.g., note taking); good mathematics background; bilingualism. But she also had to learn new cultural norms of what it means to go to school and 
improve her knowledge of English. All of this while going through adolescence. In the next and final section I look at the main points presented and use them to address the looking ahead part of this paper.

\subsection{Looking Ahead}

Throughout this paper my focus has been on the need to take a resource-based view towards the mathematics education of non-dominant students. While in the context of my work, many of these students and their families navigate varying cultural and linguistic terrains that at times may make their learning of mathematics hard, they also bring multiple resources, such as knowledge of mathematics and study habits that may go untapped; knowledge of more than one language, which can be seen as an advantage as they can provide access to more representations; experiences with mathematics at home that can be used to strengthen the connection between home and school. In Civil (2016a) I argue for the need to get a better understanding of the nature of engagement in mathematically-rich everyday practices particularly in non-dominant communities. How do parents and students participate in mathematical practices in their everyday life; how do they relate (or could) to the practices in school mathematics? As I look ahead, I wonder about the potential of the notion of culturally sustaining pedagogy (Paris 2012) for future work in mathematics education:

The term culturally sustaining requires that our pedagogies be more than responsive of or relevant to the cultural experiences and practices of young people - it requires that they support young people in sustaining the cultural and linguistic competence of their communities while simultaneously offering access to dominant cultural competence. (p. 95)

In this paper, I have argued for the need to develop an integrated model that connects mathematics teaching and learning to the cultural, social, linguistic and political contexts of non-dominant students. In particular, the case of Dina calls for teacher education initiatives that provide opportunities for teachers to engage in using their students' funds of knowledge as resources for teaching. The case of Larissa underscores the potential loss of learning opportunities when students' funds of knowledge (e.g., home language(s); different ways to do mathematics and study habits) are not developed in a culturally sustaining way. To this end, as I look ahead, I suggest that we need to work on developing stronger and meaningful communication between home and school; challenge the different valorizations given to different forms of mathematics; probe the effects of language policies on students' mathematics education; engage with teachers in conversations about the 
mathematics education of non-dominant students; and share narratives of non-dominant students' successful participation in mathematical discussions.

Acknowledgements Some of the work in this paper was funded by the National Science Foundation under grants ESI 9901275 and ESI 0424983 and by the Heising Simons Foundation, Grant \#2016-065. The views expressed here are those of the author and do not necessarily reflect the views of the funding agencies.

\section{References}

Abreu, G. de (1995). Understanding how children experience the relationship between home and school mathematics. Mind, Culture, and Activity, 2, 119-142.

Acosta-Iriqui, J., Civil, M., Díez-Palomar, J. Marshall, M., \& Quintos-Alonso, B. (2011). Conversations around mathematics education with Latino parents in two Borderland communities: The influence of two contrasting language policies. In K. Téllez, J. Moschkovich, \& M. Civil (Eds.), Latinos/as and mathematics education: Research on learning and teaching in classrooms and communities (pp. 125-147). Charlotte, NC: Information Age Publishing.

Alrø, H., Skovsmose, O., \& Valero, P. (2009). Inter-viewing foregrounds: Students' motives for learning in a multicultural setting. In M. César \& K. Kumpulainen (Eds.), Social interactions in multicultural settings (pp. 13-17). Rotterdam, The Netherlands: Sense Publishers.

Barwell, R., Clarkson, P., Halai, A., Kazima, M., Moschkovich, J., Planas, N., et al. (Eds.) (2016). Mathematics education and language diversity: The 21st ICMI study. New York: Springer.

Civil, M. (2002a). Culture and mathematics: A community approach. Journal of Intercultural Studies, 23(2), 133-148.

Civil, M. (2002b). Everyday mathematics, mathematicians' mathematics, and school mathematics: Can we bring them together? In M. Brenner \& J. Moschkovich (Eds.), Everyday and academic mathematics in the classroom. Journal for Research in Mathematics Education Monograph \#11, pp. 40-62. Reston, VA: NCTM.

Civil, M. (2007). Building on community knowledge: An avenue to equity in mathematics education. In N. Nasir \& P. Cobb (Eds.), Improving access to mathematics: Diversity and equity in the classroom (pp. 105-117). New York: Teachers College Press.

Civil, M. (2011). Mathematics education, language policy, and English language learners. In W. F. Tate, K. D. King, \& C. Rousseau Anderson (Eds.), Disrupting tradition: Research and practice pathways in mathematics education (pp. 77-91). Reston, VA: NCTM.

Civil, M. (2012). Mathematics teaching and learning of immigrant students: An overview of the research field across multiple settings. In O. Skovsmose \& B. Greer (Eds.), Opening the cage: Critique and politics of mathematics education (pp. 127-142). Rotterdam, The Netherlands: Sense Publishers.

Civil, M. (2016a). STEM learning research through a funds of knowledge lens. Cultural Studies of Science Education, 11(1), 41-59. https://doi.org/10.1007/s11422-014-9648-2.

Civil, M. (2016b). "This is nice but they need to learn to do things the U.S. way": Reaction to different algorithms. In D. Y. White, S. Crespo, \& M. Civil (Eds.), Cases for mathematics teacher educators: Facilitating conversations about inequities in mathematics classrooms (pp. 219-225). Charlotte, NC: Information Age Publishing.

Civil, M., \& Andrade, R. (2003) Collaborative practice with parents: The role of researcher as mediator. In A. Peter-Koop, A. Begg, C. Breen, \& V. Santos-Wagner (Eds.), Collaboration in teacher education: Working towards a common goal (pp. 153-168). Boston, MA: Kluwer. 
Civil, M., \& Bernier, E. (2006). Exploring images of parental participation in mathematics education: Challenges and possibilities. Mathematical Thinking and Learning, 8(3), 309-330.

Civil, M., Bratton, J., \& Quintos, B. (2005). Parents and mathematics education in a Latino community: Redefining parental participation. Multicultural Education, 13(2), 60-64.

Civil, M., \& Hunter, R. (2015). Participation of non-dominant students in argumentation in the mathematics classroom. Intercultural Education, 26, 296-312. https://doi.org/10.1080/ 14675986.2015.1071755.

Civil, M., \& Menéndez, J. M. (2011). Impressions of Mexican immigrant families on their early experiences with school mathematics in Arizona. In R. Kitchen \& M. Civil (Eds.), Transnational and borderland studies in mathematics education (pp. 47-68). New York, NY: Routledge.

Civil, M., \& Planas, N. (2010). Latino/a immigrant parents' voices in mathematics education. In E. Grigorenko \& R. Takanishi (Eds.), Immigration, diversity, and education (pp. 130-150). New York, NY: Routledge.

Civil, M., Planas, N., \& Quintos, B. (2005). Immigrant parents' perspectives on their children's mathematics. Zentralblatt für Didaktik der Mathematik, 37(2), 81-89.

Civil, M., \& Quintos, B. (2009). Latina mothers' perceptions about the teaching and learning of mathematics: Implications for parental participation. In B. Greer, S. Mukhopadhyay, S. Nelson-Barber, \& A. Powell (Eds.), Culturally responsive mathematics education (pp. 321343). New York, NY: Routledge.

Cummins, J. (2000). Language, power and pedagogy: Bilingual children in the crossfire. Tonawanda, NY: Multilingual Matters.

Díez-Palomar, J., Menéndez, J. M., \& Civil, M. (2011). Learning mathematics with adult learners: Drawing from parents' perspectives. Revista Latinoamericana de Investigación en Matemática Educativa (RELIME), 14(1), 71-94.

Gándara, P., \& Orfield, G. (2012). Why Arizona matters: The historical, legal, and political contexts of Arizona's instructional policies and U.S. linguistic hegemony. Language Policy, 11, 7-19. https://doi.org/10.1007/s10993-011-9227-2.

González, N. (2005). Theoretical underpinnings. In N. González, L. Moll, \& C. Amanti (Eds.), Funds of knowledge: Theorizing practice in households, communities, and classrooms (pp. 2546). New York: Routledge.

González, N., Moll, L., \& Amanti, C. (Eds.) (2005). Funds of knowledge: Theorizing practice in households, communities, and classrooms. New York: Routledge.

Hodge, L. L., \& Cobb, P. (2016). Two views of culture and their implications for mathematics teaching and learning. Urban Education. First published date: 11 April, 2016. https://doi.org/ $10.1177 / 0042085916641173$.

Knijnik, G. (1993). An ethnomathematical approach in mathematical education: A matter of political power. For the Learning of Mathematics, 13(2), 23-25.

Menéndez, J. M., Civil, M., \& Mariño, V. (2009, April). Latino parents as teachers of mathematics: Examples of interactions outside the classroom. Paper presented at the annual meeting of the American Educational Research Association (AERA), San Diego, CA.

Moll, L. C., Amanti, C., Neff, D., \& González, N. (2005). Funds of knowledge for teaching: Using a qualitative approach to connect homes and classrooms. In N. González, L. Moll, \& C. Amanti (Eds.), Funds of knowledge: Theorizing practice in households, communities, and classrooms (pp. 71-87). New York: Routledge.

Paris, D. (2012). Culturally sustaining pedagogy: A needed change in stance, terminology, and practice. Educational Researcher, 41(3), 93-97. https://doi.org/10.3102/0013189X12441244.

Sheridan, T. E. (1995). Arizona: A history. Tucson, AZ: The University of Arizona Press.

Suárez-Orozco, C., Pimentel, A., \& Martin, M. (2009). The significance of relationships: Academic engagement and achievement among newcomer immigrant youth. Teachers College Record, 111(3), 712-749. 
Suárez-Orozco, C., \& Suárez-Orozco, M. (2001). Children of immigration. Cambridge, MA: Harvard University Press.

Valdés, G. (1998). The world outside and inside schools: Language and immigrant children. Educational Researcher, 27(6), 4-18.

Wright, W. E. (2005). The political spectacle of Arizona's proposition 203. Educational Policy, $19,662-700$.

Open Access This chapter is licensed under the terms of the Creative Commons Attribution 4.0 International License (http://creativecommons.org/licenses/by/4.0/), which permits use, sharing, adaptation, distribution and reproduction in any medium or format, as long as you give appropriate credit to the original author(s) and the source, provide a link to the Creative Commons license and indicate if changes were made.

The images or other third party material in this chapter are included in the chapter's Creative Commons license, unless indicated otherwise in a credit line to the material. If material is not included in the chapter's Creative Commons license and your intended use is not permitted by statutory regulation or exceeds the permitted use, you will need to obtain permission directly from the copyright holder. 